
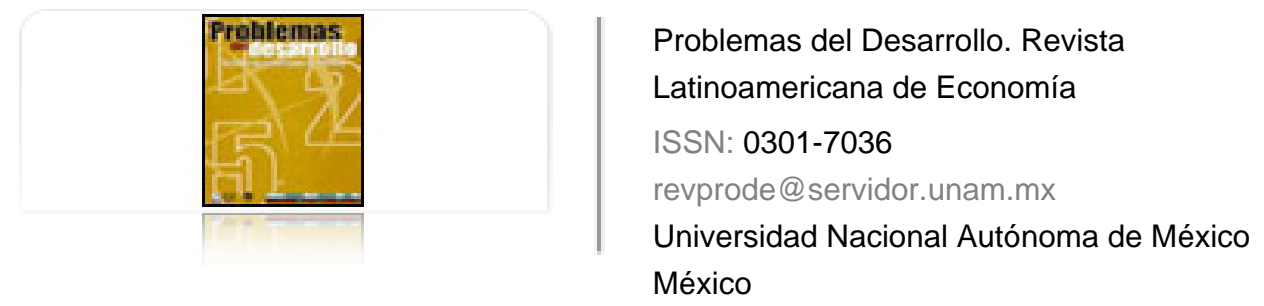

Mañán García, Oscar Mario La condicionalidad estructural de las IFIS y la autonomía de la política económica: crítica a los argumentos de la impotencia

Problemas del Desarrollo. Revista Latinoamericana de Economía, vol. 35, núm. 139, 2004, pp. 185-

207

Universidad Nacional Autónoma de México

Distrito Federal, México

Disponible en: http://www.redalyc.org/articulo.oa?id=11825939009

Cómo citar el artículo

- Número completo

- Más información del artículo

Página de la revista en redalyc.org

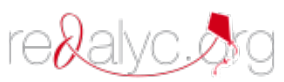

Sistema de Información Científica

Red de Revistas Científicas de América Latina, el Caribe, España y Portugal Proyecto académico sin fines de lucro, desarrollado bajo la iniciativa de acceso abierto 


\title{
LA CONDICIONALIDAD ESTRUCTURAL DE LAS IFIS Y LA AUTONOMÍA DE LA POLÍTICA ECONÓMICA: CRÍTICA A LOS ARGUMENTOS DE LA IMPOTENCIA
}

\section{Oscar Mario Mañán García*}

Fecha de recepción: 25 de octubre de 2004. Fecha de aceptación: 16 de noviembre de 2004.

\begin{abstract}
Resumen
La política de condicionalidad estructural llevada a cabo por instituciones financieras internacionales (IFIS) es criticada por poner en tela de juicio la soberanía y el albedrío de países para determinar su futuro. Las exigencias impuestas por dichas instituciones, a cambio de financiamientos para el desarrollo, a menudo se utilizan como pretexto para ocultar responsabilidades de gobiernos en fracasos económicos. Hoy día, una profunda revisión de esta condicionalidad se instala tanto a partir de críticos como de sus mismos propulsores. Sustentamos que la coyuntura es alentadora para que países emergentes hagan pesar sus especificidades económicas, sociales y sus proyectos nacionales en la negociación con organismos internacionales de crédito. No obstante, la actitud de los gobiernos no inspira optimismo desmesurado y la crítica implacable de sus opositores destila cierto fatalismo.

Palabras clave: servicios e instituciones financieras y desarrollo/condicionalidad estructural, relaciones internacionales y desarrollo, papel de las organizaciones internacionales, gobierno, política y regulación.
\end{abstract}

* Doctorante en Estudios del Desarrollo en la Universidad Autónoma de Zacatecas, México. Profesor efectivo de tiempo completo, Área de Ciiencias Sociales en el Centro Regional de Profesores del Centro, Sede Florida, Uruguay y Profesor adjunto de la Cátedra de Economía de América Latina en la Facultad de Ciencias Económicas y Administración, Universidad de la República, Montevideo, Uruguay. Correo electrónico: oscar@servidor.unam.mx

Agradezco las críticas y comentarios del Dr. Guillermo Foladori a una versión preliminar de este trabajo, empero, lo eximo de toda responsabilidad por la posición aquí asumida. 


\section{Abstract}

This study criticized the policy of structural conditionality practiced by the international financial institutions (IFIS), which compromises the sovereignty and free will of countries with respect to their future. The demands imposed by these institutions, in exchange for development financing, are used at least as a pretext to conceal the responsibility of governments in economic failures. Today, a profound revision of this conditionality is being made, promoted by both its critics and its proponents. We argue that the situation is encouraging for the emerging countries, giving weight to their economic and social specificities, as well as their national projects, in their negotiations with the international lending agencies. Nonetheless, the attitude of governments does not inspire optimism, while opposition party criticisms are leading to a certain fatalism.

Key terms: financial institutions and structural development/conditionality. International linkages to development; Role of international organizations, financial institutions and services, government policy and regulation.

\section{Résumé}

C'est une critique de la politique de Conditionnalité structurelle pratiquée par les institutions financières internationales (IFIS), qui compromettent la souveraineté et l'arbitre des pays en ce qui concerne la détermination de leur futur. Les exigences imposées par ces institutions, en échange de financements pour le développement, sont utilisées le plus souvent comme des prétextes pour cacher la responsabilité des gouvernements dans les échecs économiques. Actuellement, on réalise une révision en profondeur de cette conditionnalité, promue aussi bien par ses critiques que par ses propulseurs. On soutient que la conjoncture encourage les pays émergeants pour qu'ils puissent faire peser leurs spécificités économiques et sociales, de même que leurs projets nationaux, dans leurs négociations avec les organismes internationaux de crédit. Cependant, l'attitude des gouvernements n'inspire pas d'optimisme et la critique de la part de ses opposants distille un certain fatalisme.

Mots clés: institutions financières et développement/conditionnalité structurelle, international linkages to development.

\section{Resumo}

Critica-se a política de condicionalidade estrutural praticada pelas instituições financeiras internacionais (IFIS), que comprometem a soberania e o arbítrio dos países em relação à determinação do seu futuro. As exigências impostas por tais instituições, em troca de financiamentos para o desenvolvimento, são utilizadas freqüentemente como pretexto para ocultar a responsabilidade dos governos nos fracassos econômicos. Hoje em dia se realiza uma profunda revisão desta condicionalidade, promovida tanto por seus críticos, como por seus propulsores. Sustentamos que a conjuntura é alentadora para os países emergentes fazerem pesar as suas especificidades econômicas e sociais, assim como os seus projetos nacionais, em suas negociações com os organismos internacionais de crédito. Não obstante, a atitude dos governos não inspira otimismo e a crítica de seus opositores destila certo fatalismo.

Palavras-chave: instituições financeiras e desenvolvimento/condicionalidade estrutural. international linkages to development; role of international organizations, financial institutions and services, government policy and regulation. 


\section{Introducción}

$\mathrm{L}$

os últimos veinte años de historia social y económica de América Latina estuvieron signados por profundos cambios estructurales (Valenzuela, 1991) enmarcados en el proceso de globalización.

Las instituciones financieras internacionales (IFIS: Banco Mundial, Fondo Monetario Internacional, Banco Interamericano de Desarrollo, entre otras) cargaron con la gestión de dicho cambio estructural, debido a su aporte de fondos para implantar proyectos de desarrollo en países emergentes, préstamos para afrontar crisis económicas o vencimientos de compromisos financieros y asistencia técnica.

Estas notas se refieren a la llamada condicionalidad estructural, forma dominante de imponer políticas consensuadas en Washington y que pusieron en marcha dicho cambio estructural. Hoy día estos instrumentos de política no parecen tan exitosos a ojos de sus propios promotores (IMF, 2001; IMF-World Bank, 2001; Kuczynski y Williamson, 2003) y, a su vez, cargan con la crítica generalizada de ámbitos académicos, sociales, oposiciones políticas, e incluso varios gobiernos.

Sostenemos la posibilidad cierta de la autonomía de la política económica, pese a corsets que estos instrumentos pretenden imponer. Buscamos desmitificar la imposibilidad de enfrentar la condicionalidad, discurso todavía muy recurrente en muchos gobiernos latinoamericanos y, curiosamente, en los críticos más acérrimos de planes globalizadores. Ambos discursos tienen igual corolario político: el inmovilismo.

En la siguiente sección presentaremos lo que se entiende por condicionalidad estructural y sus alcances. En la tercera, el vínculo de la misma con la estructuración del nuevo orden económico vigente desde los años ochenta. El apartado cuatro desarrolla algunos mitos popularizados acerca de la condicionalidad y su funcionalidad tanto para los sostenedores de estas políticas, como para gobiernos que creen y difunden esas creencias. El quinto rescata las críticas actuales a la aplicación de dichas políticas y plantea cinco dimensiones de las primeras. El punto seis ejemplifica la suerte de estas políticas y el enfrentamiento que ha generado, si tomamos en cuenta distintas realidades del acontecer latinoamericano. Por último, dejamos algunas consideraciones a modo de conclusión para puntualizar: $a$ ) el momento especialmente interesante que tienen los países para reformular las políticas vigentes en las IFIs; y $b$ ) la importancia de una acción conjunta que rescate las contradicciones que presentan dichas políticas, y en las cuales encontramos más fisuras de las que críticos y defensores están dispuestos a aceptar. 


\section{¿Qué es condicionalidad estructural?}

Según el Fondo Monetario Internacional (FMI):

Cuando un país miembro obtiene un préstamo del FMI, las autoridades del país se comprometen a aplicar reformas económicas y financieras, requisito que se conoce con el nombre de "condicionalidad". La condicionalidad brinda al FMI la seguridad de que el préstamo otorgado se utilizará para hacer frente a las dificultades económicas del prestatario y que el país podrá rembolsarlo de manera oportuna, de forma que los fondos de la institución se mantengan a disposición de los demás países miembros que los necesiten. En los últimos años, el FMI se ha centrado en focalizar y racionalizar las condiciones a las que está sujeto el financiamiento de la institución a fin de fomentar la identificación de los países con políticas sólidas y eficaces (FMI, 2002).

Se entiende por condicionalidad los requerimientos que las IFIS piden a los países para que éstos accedan a créditos de fondos multilaterales. En general, el financiamiento aparece ligado al cumplimiento de objetivos acordados para satisfacer en forma adecuada los compromisos asumidos y, a su vez, mejorar las situaciones críticas que hicieron indispensable el endeudamiento. La condicionalidad, por lo tanto, tiene como objetivo cuidar del riesgo moral que tendría la no aplicación de los recursos prestados a las exigencias para las cuales se solicitaron. De aquí que la participación de organismos internacionales en alentar la mejor combinación de recursos y políticas para lograr los fines acordados no sea de por sí una mala idea.

El problema se ha suscitado en las últimas décadas con la extensión de dicha condicionalidad a otros espacios de la economía considerados parte de la soberanía nacional, ya sean sectores públicos estratégicos (energía, agua, entre otros) así como a la organización del sistema de salud o los gastos en educación.

Las medidas de política que deberá adoptar el país no sólo tendrán como objetivo resolver los problemas inmediatos de balanza de pagos, sino también sentar las bases de un crecimiento económico sostenido logrando una estabilidad económica más amplia: por ejemplo, medidas para contener la inflación o reducir la deuda pública. Las medidas de política también deberán abordar los problemas estructurales que obstaculizan un crecimiento sólido, tales como la liberación de los precios y del comercio, las medidas para fortalecer los sistemas financieros o mejoras en el ámbito de la gestión de gobierno (FMI, 2002).

Para asegurarse el cumplimiento de los objetivos trazados en las largas y arduas negociaciones que llevan los gobiernos con dichas IFIs, es muy común que los desembolsos de dinero de los créditos acordados estén escalonados y debidamente vinculados a medidas concretas o, bien, a resultados económicos parciales. Al seguir el caso del FMI, tenemos que hay condiciones a priori para ganar el derecho de negociar la ayuda financiera. Las llamadas acciones previas son aquellas que tienen lugar antes del primer desembolso monetario e, incluso, previo a que el directorio ejecutivo de la institución considere la solicitud de crédito. Dichas acciones son: “por ejemplo, el reajuste del tipo de cambio a un nivel 
sostenible, la eliminación de los controles de precios o la aprobación oficial del presupuesto público de acuerdo con el marco fiscal del programa" (FMI, 2002). ${ }^{1}$

Por supuesto, la evaluación de programas (i.e. del FMI) tiene una serie de criterios que se deben satisfacer para que los desembolsos se hagan efectivos en cada uno de los niveles acordados. Los criterios de ejecución dan cuenta de en qué medida se fueron satisfaciendo metas indicativas preestablecidas y, con dicho avance, éstos cobran una expresión cuantitativa o estructural. Los criterios de ejecución cuantitativos hacen referencia a los estrictamente macroeconómicos (reservas internacionales, agregados monetarios y de créditos, saldos fiscales o préstamos externos), mientras que los criterios de ejecución estructurales tienen que ver con acuerdos específicos que se lograron en cada caso acerca de la calidad del crecimiento futuro. Es decir, qué sectores se reestructurarán, para qué fines, entre otros.

Hay también parámetros de referencia para decidir la suerte de tal o cual programa de apoyo a un país determinado, mismos que permiten ajustes para mejorar su ejecución. Aquí caben los necesarios para endurecer o, bien, flexibilizar la aplicación de políticas acordadas, con ciertos resultados a la vista. Para tales efectos, el FMI maneja los llamados parámetros de referencia estructurales y los exámenes de programa. Los primeros, permiten evaluar cambios estructurales y su evolución, mientras que los segundos ayudan a ajustar políticas llevadas a cabo, de acuerdo con su relativo éxito o fracaso según las metas del programa. Dichos criterios, en otras ocasiones, contribuyen a mejorar las relaciones de IFIS con los países y no interrumpen propiamente apoyos económicos.

A grandes rasgos apuntamos la grafía institucionalizada en la cual operan las medidas de condicionalidad estructural, mismas que sirvieron para instaurar la etapa actual de globalización capitalista. Su relativo éxito debe buscarse justamente en la construcción de ese marco institucionalizado para la regulación de las transacciones internacionales (de todo tipo) ad hoc a los intereses del capital-dinero de préstamo. Su fracaso quizá esté en la vulnerabilidad macroeconómica y social, acompañada de la inconsistencia política que trajo aparejada.

\section{Condicionalidad y nuevo orden económico}

Más allá de las razones explícitas de los protocolos de fundación de las instituciones internacionales, éstas extendieron sus potestades y la condicionalidad sustentó lo que John Williamson (2000) nominara Consenso de Washington, generando así, las más drásticas reformas estructurales que conocieran los estados emergentes en los últimos años. Para ser

1 Cada uno de estos pasos puede corroborarse con la experiencia uruguaya de 2002, incluso, la ver güenza pública que implicó la votación parlamentaria del presupuesto a carpeta cerrada (sin debate anterior) debido a que se estaba a la espera de un crédito puente del gobierno de Estados Unidos que adelantaría del FMI pero que, a su vez, exigía las condiciones estipuladas en dicho presupuesto. 
exactos, alentaron u exigieron apertura comercial y financiera, disminución del aparato estatal con las consabidas privatizaciones, equilibrios macroeconómicos basados en políticas procíclicas que restringieron la acumulación interna y sostuvieron reducciones salariales como forma de reestructurar costos y aglizar la actividad económica. Ello determinó una reestructuración de costos de funcionamiento estatal y empresarial y de su respectivo financiamiento, conformación social diferente, otra inserción internacional y empobrecimiento creciente que, muchas veces, generó crisis políticas y sociales de magnitud.

Se conjugaron varias razones propias de lo que se ha llamado "nuevo orden mundial" (Petras y Veltmeyer, 2003). A partir del alejamiento del dólar de su referencia con el oro y el acuerdo de Bretton Woods que lo sustentó, los flujos dinerarios se multiplicaron y salieron de sus letargos en busca de nuevos negocios. Para dichos fines, países emergentes fueron fundamentales para generar mercados financieros ampliados y espacios para la acumulación mundial.Estos flujos forjaron problemas de deuda y, en consecuencia, hicieron temblar al sistema financiero mundial en la década de los ochenta. Tales países se volvieron más vulnerables, perdieron oportunidades de desarrollo y retrocedieron en el tiempo, en términos de riqueza. Aquí LAS IFIS cobraron importancia sustancial para la reorientación del desarrollo, pusieron la tilde en la ampliación del mercado mundial, el libre flujo de capitales y recursos (con excepción de mano de obra), sin descuidar el repago en un plazo mediano - y cada vez más acotado — de créditos otorgados para tales fines.

El desarrollo implica un proceso social complejo, el cual debe combinar fuerzas sociales — con intereses encontrados muchas de ellas - y lograr consensos que articulen un equilibrio móvil de dichos intereses como sustento de la viabilidad económica y política perseguida. Por supuesto, a nadie llamará la atención que el horizonte temporal de la recuperación de créditos no corresponda con los avatares del proceso social descrito. Por lo tanto, y desde la teoría económica neoclásica más ortodoxa, ${ }^{2}$ se da prioridad a objetivos de cuenta e instrumentos tecnocráticos que permitirían cumplir compromisos asumidos y garantizarían el retorno de flujos dinerarios (con sus respectivas ganancias) por sobre los objetivos de desarrollo social. Así se inscribieron las reformas económicas que dilapidaron activos estratégicos de países (sector energético, comunicaciones, líneas aéreas, otros recursos naturales) para que se trasmutaran en fondos de repago de deudas pero que, además, generaran condiciones para los mercados ampliados (sustentados en libre flujo de capital-dinero de préstamo) que son la esencia de la globalización.

2 Ramos (1986:1) rescata la definición más recurrente de esta corriente que en Estados Unidos se co noce como neoconservadurismo (a la derecha del centro y económicamente conservador) y apunta su nacimiento en la gran Chicago (refiere a las universidades de Columbia, Chicago y Stanford). El vínculo con el adjetivo conservador puede rastrearse a la sobredeterminación de los objetivos de cuenta sobre los de desarrollo social. Curiosamente, la traducción al español más conocida es neoliberalismo. 
Son características de la etapa actual: adelgazamiento del Estado, planes estabilizadores —que pasaron indefectiblemente por ajustar gastos públicos a sus expresiones mínimas y en especial las inversiones ${ }^{3}$ que, a su vez, redujeron los salarios a niveles de infrasubsistencia-, pérdida de regulación nacional de la economía y creciente dependencia de los flujos externos de capital.

\section{Algunos mitos destacables y su funcionalidad}

El desconocimiento de las exigencias reales de los créditos internacionales y los mecanismos para hacerlos efectivos ayudan a ocultar la falta de alternativas de gobernantes. La referencia al discurso de la condicionalidad de IFIS disimula responsabilidades de algunos representantes locales de gobiernos o parlamentos, quienes se refugian en los conocidos argumentos de impotencia: "no hay más remedio". ${ }^{4}$ Muchas veces, las administraciones gubernamentales eligen el camino más fácil al tomar a rajatabla las proposiciones de instituciones internacionales de crédito, sin proponer alternativas ni tomar en cuenta momentos económicos y, en la mayoría de los casos, impulsados por salvar un periodo de gobierno.

Lo anterior abona un argumento esgrimido corrientemente que se refiere a la corrupción de los gobiernos (en especial de los latinoamericanos). Las IFIS y, en particular, el Banco Mundial (2000) sostienen el argumento de la corrupción como una condición inherente a los políticos de países pobres. Desde los críticos del nuevo orden, se utiliza similar sustento para analizar la acción de intelectuales que integran la dirección política de los estados (Petras y Veltmeyer, 2003:165-178). Ambos argumentos pecan de cierto racismo $\mathrm{y}$, específicamente, de no examinar el vínculo que se establece entre algunos sectores de las élites gobernantes y sus homólogas internacionales, y cómo aquellas defienden sus intereses en un contexto de correlación de fuerzas también disminuida.

Por su parte, los sindicatos y sectores populares se levantan muchas veces contra la actitud de las instituciones internacionales de crédito ante la extensión de dicha

Aquí hay un conflicto entre el discurso dominante y la acción concreta de los países. El gasto público cae por el lado de inversiones, cosa coherente con el discurso dominante explícito, el cual sostiene que la actividad privada es más eficiente que la pública, y con el implícito que apuntala el "nuevo orden internacional" (Petras y Veltmeyer, 2003:117 132). Si tenemos la referencia de la última década larga (los noventa hasta el presente) el gasto estrictamente social aumentó en América Latina (CEPAL, 2002a), cuestión que no ajusta con el discurso liberalizador y eficientista del crecimiento económico y del bienestar como consecuencia necesaria. Tal vez, esto último sí tenga que ver con un discurso implícito que se hace explícito a partir de las reformas de segunda generación en la mitad de los noventa: la preocupación por la gobernabilidad del nuevo orden. El gasto social en dicho en tendido estaría controlando efectos perversos (no deseados) de un modelo económico por demás excluyente.

4 La expresión popular en inglés es tiNa (acrónimo de There Is No Alternative,) y se le adjudica a Margaret Thatcher, ex premier británica (George, 2002:7). 
condicionalidad a terrenos que son patrimonio de la soberanía y del arbitrio de los países. También los gobernantes, al buscar salvar sus responsabilidades y alentar ese odio eterno que las sociedades no esconden ante instituciones como el FMI o el BM por haber digitado su política económica con resultados bastante lejanos a los que se podrían tildar de exitosos (Kuczynski y Williamson, 2003).

Si la vulnerabilidad social instalada en mercados emergentes tiene que ver con la aplicación de políticas implantadas por las IFIs, también se relaciona con la adopción acrítica de ellas por gobernantes autoconvencidos. Es decir, con iniciativas económicas que no siempre corresponden con las necesidades propias de estos países.

Sin embargo, la mitología de que estas instituciones son todopoderosas, inviolables, obcecadas y perversas, en la mayoría de los casos sirve para proteger a malos gobiernos, y para justificar las oposiciones por su inacción, las cuales sueñan con relevar a dichos gobiernos. Si bien es cierto, como lo señalan Petras y Veltmeyer (2003) o el propio Williamson (2000), que las IFIS son parte de un programa político delineado y planificado con base en un deber ser construido y acordado por países industrializados, no menos cierto es que tales designios no están exentos de contradicciones.

La controversia se manifiesta cuando algunos países que presentan problemas para ser considerados sujetos de créditos, dada la institucionalidad de las IFIS, deciden recurrir a socios mayoritarios (i.e. Estados Unidos) para ejercer presión sobre las autoridades de estas IFIS (los casos de México y Uruguay son ejemplos dignos). Cabría aquí separar las aguas, una cosa es la política institucionalizada de las IFIs, y otra que los países recurran al mercado de tráfico de influencias para torcer la balanza a su favor. En diciembre de 1994, el gobierno de Estados Unidos tomó la iniciativa (incluso en contra del Congreso) de apoyar financieramente a México (y movilizó influencias para complementar la ayuda), lo que a la postre salvara a los tenedores estadounidenses de bonos públicos mexicanos. En el caso uruguayo hay pruebas suficientes entre las reminiscencias del FMI a otorgar créditos sin una reestructura del sistema financiero (por su inviabilidad de largo plazo) y la presión de Estados Unidos para que sí se hiciese efectivo. La razón de la fuerza primó: Uruguay obtuvo sus apoyos económicos, así como otros costos no explícitos pero intuidos por todos. ${ }^{5}$

En la misma crisis bancario-financiera uruguaya (estrechamente vinculada a la depresión argentina) y contra todo pronóstico, las autoridades del FMI le aconsejaron al gobierno la búsqueda de una posible reprogramación de deuda (en principio con tenedores priva-

5 Los compromisos asumidos fuera de la institucionalidad y la falta de transparencia fomentan con razón todo tipo de especulaciones. Las mentes más sagaces (apoyadas en alguna carta en inglés muy parecida a la presentada luego por Uruguay para alentar una sanción a Cuba por la violación de derechos humanos) vinculan el crédito puente otorgado por el Departamento del Tesoro de Estados Unidos, y el posterior apoyo del FMI, con el papel del país en la ofensiva internacional contra Cuba. Sin duda, y más allá de polémicas, este hecho tampoco se enclavaba en las mejores tradiciones de su diplomacia. 
dos) lo cual implicaba aceptar el default. El gobierno se opuso en principio (curiosamente coincidente con parte de la izquierda) alegando que una reprogramación (u otro adjetivo que implicara lo mismo) bajaría aún más la nota deprimida que ya ostentaba el país en mercados financieros internacionales. ${ }^{6}$ Tanto el gobierno como parte de la izquierda no habían asimilado aún lo que el FMI, es decir, el fin (y fracaso) del modelo de desarrollo sostenido por todos ellos hasta un año atrás.

El experimento cuasi de laboratorio que resultó Argentina en los últimos dos años presenta un valiosísimo aprendizaje para mostrar la inoperancia del mito de la necesidad imperiosa de flujos de capitales (o créditos externos) para el funcionamiento económico contemporáneo (Lavagna, 2003).

\section{Condicionalidad y críticas}

Las dimensiones de la crítica a las estrategias de condicionalidad estructural seguidas por las IFIS, que hoy justifican una revisión, son al menos cinco. Primero, las presiones políticas provenientes de grupos antiglobalización se multiplican en distintos foros internacionales (desde Seattle 1998 hasta Mumbai 2004) y cuestionan las consecuencias excluyentes y antipopulares de los manejos de dichas políticas llevadas a cabo por esas instituciones, con la anuencia de los gobiernos (George y Wolf, 2002; González, 2004). Segundo, la acción de algunos países con posturas que interpelan fuertemente la condicionalidad comienzan una búsqueda de consenso internacional para limitar su ámbito de acción (Lavagna, 2003; Lula, 2003). Tercero, críticas de organismos internacionales que mantienen cierta independencia académica basada en una tradición importante del pensamiento latinoamericanista, como la CEPAL (Martner y Ocampo, 2002; entre otros). Cuarto, fisuras que estas instituciones tienen en la práctica concreta de gestión del desarrollo, que da como corolario desprendimientos internos y profundas críticas al accionar de las mismas (Stiglitz, 2001, 2003). Quinto, estudios autocríticos que evalúan estrategias e instrumentos de las IFIS (IMF, 2001; IMF-World Bank, 2001; sólo por citar algunos) de hecho llevan a que se rediscuta la condicionalidad a la luz de limitados resultados económicos. Ejemplifiquemos estas cinco dimensiones.

Primero, desde mitad de los noventa, fundamentalmente en Europa, comenzó una fuerte movilización que cuestiona el desempeño de las principales instituciones financieras FMI y вм (Madrid, 1994), también ante la UE o el ALCA (Madrid, 1995; Amsterdam, 1997; Colonia, 1999; Niza, Gotemburgo, Quebec y otras), el G-7 (Colonia, 1999) y el Acuerdo Multilateral de Inversiones (Francia, Canadá, Estados Unidos, Malasia, Filipinas, India,

6 La obstinación del gobierno por sostener un sistema financiero costoso, hipertrofiado e ineficiente lo llevó a dilapidar las reservas internacionales $(1.200 \mathrm{mdd}$ ) y a la potenciación de la deuda externa que, para el año 2004, supera en $11 \%$ el nivel del producto (a pesar del éxito del canje de deuda con privados que difirió vencimientos que rondaban el monto de las exportaciones). 
Brasil) (González, 2004). Dichas movilizaciones se institucionalizaron a partir de Seattle y dieron lugar a múltiples organizaciones (Movimientos de Resistencia Global y sus filiales nacionales) que también tienen como objetivo los principales organismos que regulan el capitalismo, FMI, BM, OMC, G-7 y Foro Económico Mundial (González, 2004; George y Wolf, 2002). Las movilizaciones se extendieron desde el centro (Washington, Melbourne, Praga, Davos, Barcelona) a la periferia (Chiang Mai, Bangkok, México, entre otros) y también desde una crítica a instituciones financieras y de regulación económica al cuestionamiento de las clases políticas de los mismos países (Washington, México, Argentina) (González, 2004; George y Wolf, 2002).

Segundo, dos ejemplos recientes de cuestionamiento desempeño de las IFIS se localizan en América Latina, por un lado Argentina, con su actitud desafiante al afrontar su última crisis y, por otro, Brasil, con su presidente que concurrió tanto al Foro Social Mundial de Porto Alegre, como al Foro Económico Mundial de Davos. El caso argentino, hasta ahora exitoso, buscó una alternativa a las propuestas de las IFIS, con las cuales incluso se llegaron a tensar relaciones. Lula, por su parte, sostuvo (ante críticos y defensores de la globalización) la necesidad de cambios en organizaciones internacionales y una dura crítica al proteccionismo de países industrializados (mismos que sostienen un discurso de libre comercio que no hacen recíproco) y bregó por la unión de países pobres desde América Latina hasta África para luchar contra el hambre (Lula, 2003; Mekay, 2003).

Tercero, trabajos vinculados a la CEPAL levantan la voz acerca del carácter contradictorio de las propuestas de estos organismos que defienden la institucionalidad democrática y, al mismo tiempo, coartan la libertad de elegir alternativas de desarrollo de manera soberana.

El alcance de este tema va mucho más allá de la esfera económica. Tiene que ver con los objetivos más amplios de democracia a escala mundial. No tiene sentido, en efecto, promover la democracia a nivel mundial, si los procesos políticos representativos y participativos a nivel nacional no van a tener ninguna posibilidad de determinar las estrategias de desarrollo económico y social, incluida la mezcla particular de políticas a través de las cuales cada país garantiza su estabilidad macroeconómica. Ninguno de estos resultados se logrará, y además carecerá de sostenibilidad política, si las instituciones y las agencias de ayuda internacional se apropian de esta función (Martner y Ocampo: 2002).

Cuarto, el premio Nóbel de economía, Joseph Stiglitz es una de las voces disidentes más importantes en últimos años y crítico del desempeño de las IFIS —a la hora de imponer sus políticas - y, en particular, del FMI. Stiglitz (2001:263) revela cómo después de la crisis de México de 1994 y su posterior recuperación, la misma receta se aplicó en otras emergentes en Indonesia, Corea, Rusia, Brasil y Argentina, con resultados que "podrían situarse entre el mero fracaso y el desastre". Su crítica al FMI es implacable, por la tozudez con que éste afronta distintas experiencias y la manera en que impone sus condiciones en aras de la aplicabilidad de políticas propuestas (Stiglitz, 2003:64-65). 
Quinto, los estudios de autocrítica del FMI (2001) y el IMF-WB (2001) sostienen que:

a) la "propiedad" de los programas de ajuste es esencial para un adecuado funcionamiento del financiamiento de emergencia del FMI; $b$ ) en consecuencia, "la condicionalidad no debería infringir la soberanía nacional"; c) los programas de ajuste debieran ser diseñados para "permitir a un país que consiga una balanza de pagos sostenible en el mediano plazo con una tasa de crecimiento aceptable y sostenible sin efectos de contagio negativos para los países vecinos"; y $d$ ) "un elemento esencial de las políticas del FMI debería ser la salvaguarda de los recursos del Fondo" (IMF-World Bank, 2001, citados por Martner y Ocampo: 2002).

Los estudios revisados apuntan que la condicionalidad fue más efectiva cuando se limitó a pocos elementos vinculados al macrodesempeño de los países y en la medida que los programas fueron tomados como propios por los gobiernos (apoderados o tomados en propiedad), con cierta dosis de flexibilidad que permitió incluir especificidades de las economías y las sociedades en las cuales se aplicaron.

Estas críticas sustentan la tendencia del debate contemporáneo que busca enclaustrar dicha condicionalidad en parámetros históricos (desde los cincuenta hasta los ochenta), es decir, al apuntar únicamente al manejo macroeconómico de los países y, a mantener sustentabilidad de mediano plazo para el orden de las cuentas básicas.

\section{Crítica de la realidad y alternativas emergentes}

La génesis de las iniciativas económicas fondomonetaristas tenían la justificación teórica de enfrentar lo que hasta el momento (principios de los setenta) era un hecho desconocido para la teoría y la acción económica: el stagnacionismo (Rodríguez, 2001). En el plano teórico había problemas para explicar esta modalidad de estancamiento e inflación. Los keynesianos sostenían que expansión monetaria y gasto traerían efectos positivos para la producción (demanda y empleo) y coincidían con los monetaristas en que los precios se aumentarían a su vez con la producción. Pero a diferencia de los últimos, pensaban que la expansión de precios no acarrearía consecuencias negativas para la producción en el corto plazo. Por lo tanto, "era una teoría de inflación y deflación, pero no de recesiones agudas" (Ramos,1986:13). La realidad de los sesenta y setenta ponía en tela de juicio el keynesianismo dominante que había inspirado las políticas económicas de las golden ages (Maddison, 1982: Cuadro 4.11:120) del periodo de posguerra. El stagnacionismo interpelaba a la teoría ya que ésta sostenía que la inflación aparecía cuando se colmaba la capacidad productiva y no antes (Ramos, 1986:14). El nuevo monetarismo buscó crear reglas objetivas de expansión monetaria para enfrentar el anticipo que los agentes económicos hacían de los problemas fiscales derivados de la intervención estatal desmedida. Es así que sus recomendaciones de política fueron procíclicas y no contracíclicas como sostenía el keynesianismo. 
Entender el fracaso económico de dichos programas implica, a su vez, conocer el juego dialéctico entre las políticas llevadas a cabo y los cambios que lograron, cuestión que hace inapropiada también a la teoría. Por un lado, se proponían reglas macroeconómicas muy rígidas, expansiones cuantitativas determinadas para países grandes y tipos de cambio fijos para los pequeños. Los modelos de atraso cambiario (en sus diversas modalidades) muy populares en América Latina fracasaron, tuvieron una primera etapa de resultados positivos para la retracción de procesos inflacionarios y una segunda etapa devastadora para la acumulación interna de los países (pérdida de competitividad). Por otro lado, se impuso la máxima estructuralista de que la inflación tiene sus raíces en el funcionamiento económico y que dichos modelos de retracción monetaria acumulan la inflación pero no terminan con ella. A la postre, todos esos modelos acabaron en implosiones inflacionarias, las cuales tuvieron efectos más perniciosos que los procesos hiperinflacionarios anteriores que intentaron curar (Mañán, 1999). ${ }^{7}$

Las reformas económicas terminaron por generar una segmentación social muy fuerte y concentrando el poder en minorías reducidas, cuestión que implicó desvinculación entre expansión monetaria e inflación. Si aceptamos el supuesto estructuralista de la inflación y sostenemos que la puja distributiva había explicado en el pasado buena parte del alza de precios, hoy, ante la igualación hacia abajo de sectores sociales y la pérdida de poder de regateo de distintos grupos, la inflación se retrajo pero el desempleo y la pobreza aparecen en primer plano. ${ }^{8}$ Puede corroborarse aquí un nuevo desafío para la teoría, dando fe de ello las múltiples e inapropiadas estimaciones de procesos inflacionarios del mismo FMI en crisis posteriores a 1994.

En América Latina la evaluación de reformas es negativa: el crecimiento es menor que en las décadas precedentes (gráficas 1 y 2), el desempleo aumentó (Gráfica 4), la desigualdad y la pobreza también (gráficas 5 y 6 ) "las perspectivas de progreso son sombrías [...] e incluso la confianza en la democracia se ha debilitado" (Stiglitz, 2001:276; CEPAL, 2002b). Empero, la práctica económica contemporánea ha generado condiciones para que algunos países latinoamericanos puedan reconstruir un proyecto político regional que, por lo menos, apunte a pesar más en decisiones de organismos multilaterales que tratan de gestionar la globalización. A la vez que surgen enseñanzas que interpelan las políticas sostenidas en los últimos veinte años.

7 Esto puede sostenerse, por ejemplo, con una confrontación de indicadores económicos y sociales de América Latina en la década de los setenta con los correspondientes a los ochenta y noventa (CEPAL, 2002a).

8 Tal vez la inflación no era sólo ni fundamentalmente producto de la expansión monetaria, sino que la articulación social (logradas con la égida de los estados de bienestar) jugaba un papel decisivo. Los planes que sí fueron efectivos para la estabilidad macroeconómica interna de los países, no se vincularon positivamente con la expansión productiva ni con la mejora de variables de bienestar social. Por el contrario, contribuyeron a la segmentación y a la vulnerabilidad social hoy existente. De esta realidad surge un nuevo agujero para la teoría económica: la relación entre variables monetarias y reales y sus consecuencias en el bienestar, dadas las nuevas estructuras sociales. 


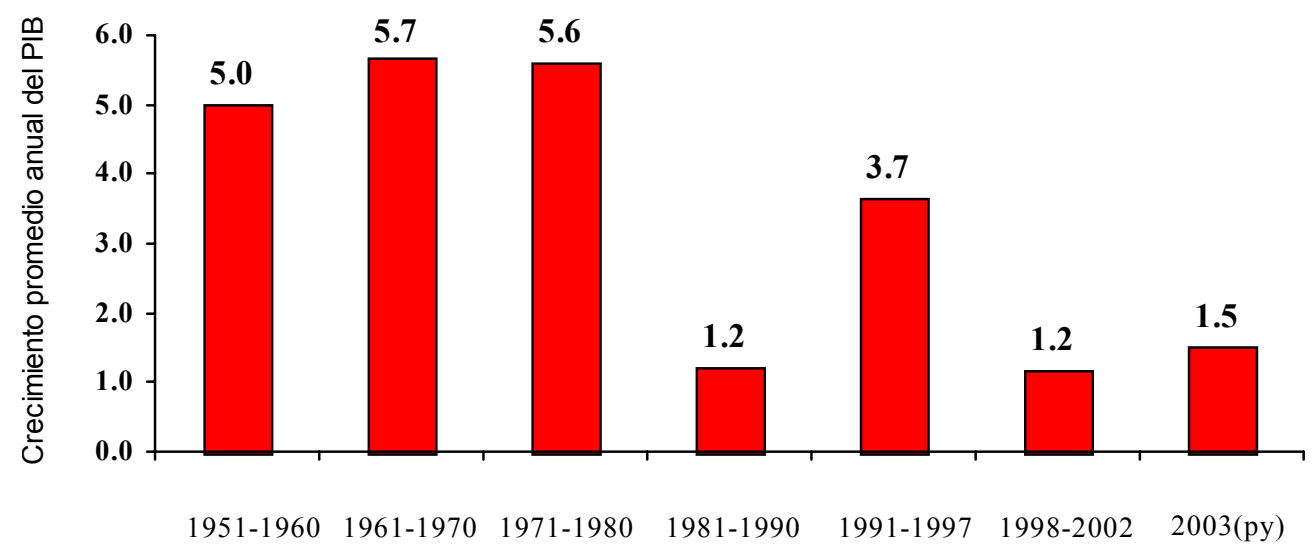

Gráfica 1. Crecimiento económico de América Latina y el Caribe.

Fuente CePal, Panorama Social de América Latina y el Caribe 2003, CEPAL, Santiago, 2003.

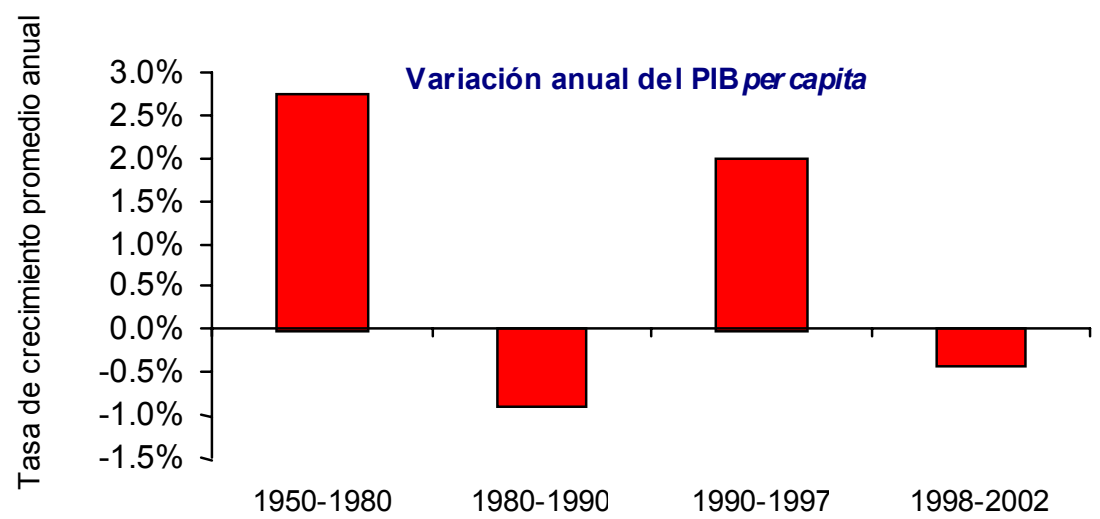

Gráfica 2. En 2002 se completó media década perdida en la región.

Fuente: CEPAL, Panorama Social de América Latina y el Caribe, CEPAL, Santiago, 2002. 


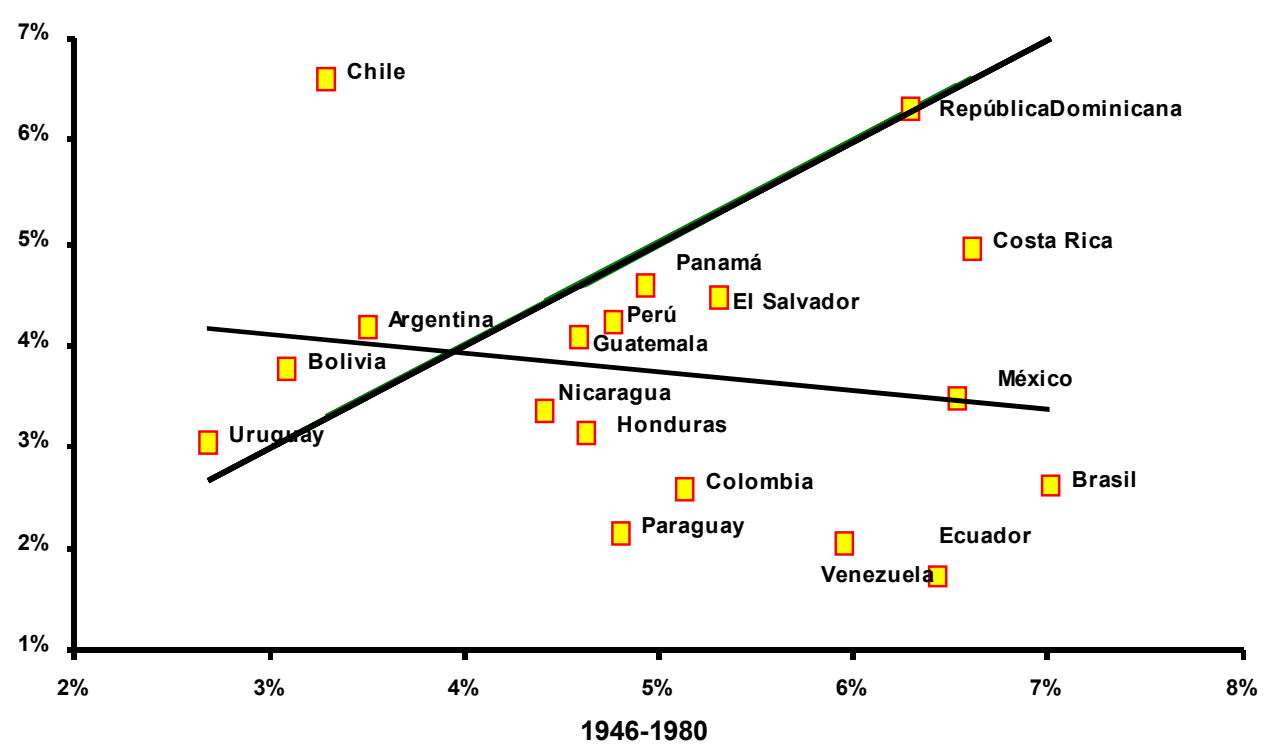

Gráfica 3. Crecimiento promedi del PIB.

Fuente: CEPAL, Panorama social de América Latina, Santiago, ILPES, 2003.

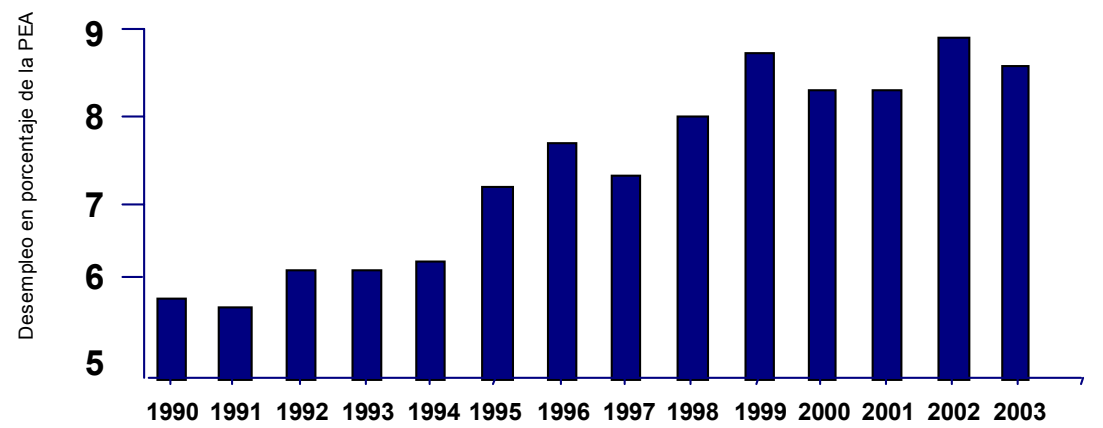

Gráfica 4. Desempleo en América Latina.

Fuente: CEPAL, Situación y perspectivas: estudio económico 2002-2003, CEPAL, Santiago, 2003. 


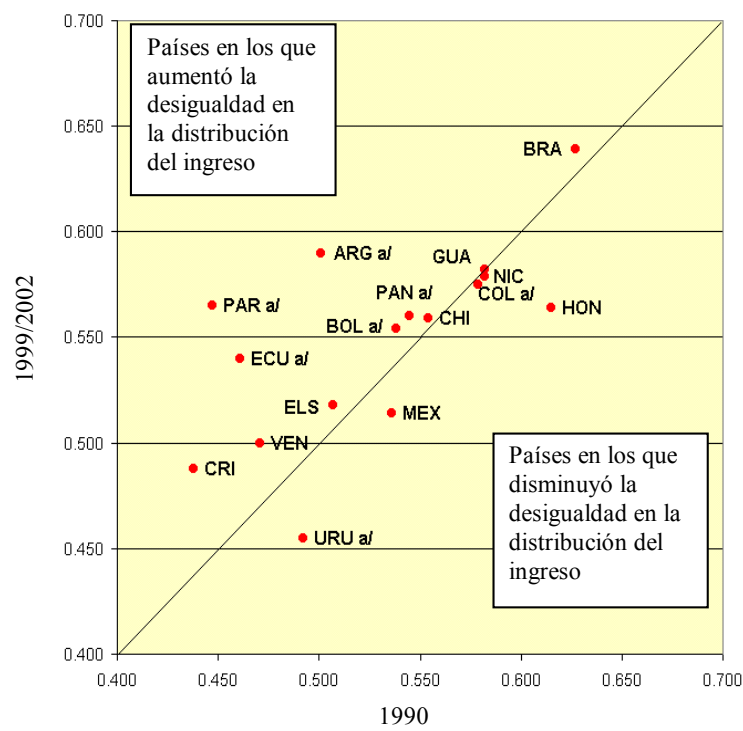

Gráfica 5. América Latina (16 países): cambios en el coeficiente de Gini de desigualdad en la distribución del ingreso.

a/ Áreas urbanas de Bolivia, Colombia, Ecuador, Panamá y Uruguay. Los datos de Argentina corresponden al gran Buenos Aires.

Fuente: CEPAL, Situación y perspectivas: estudio económico 2002-2003, CEPAL, Santiago, 2003.

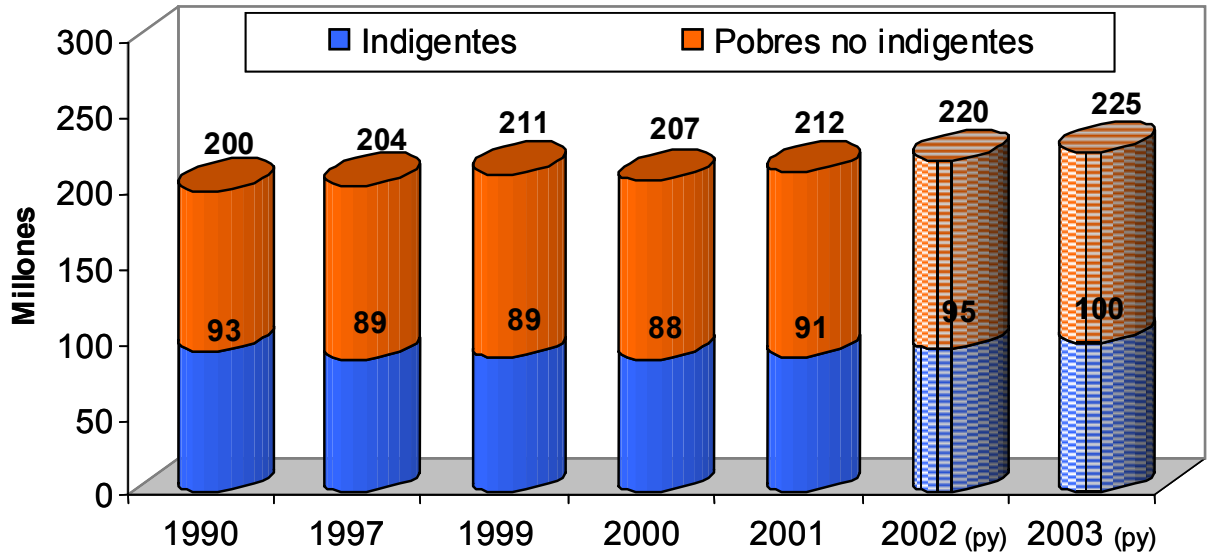

Gráfica 6. América Latina (19 países): población pobre e indigente (millones de personas).

Fuente: CEPAL, Panorama social de América Latina y el Caribe, 2003, CEPAL, Santiago, 2003. 
Chile confirma lo aquí apuntado: lleva más de quince años sin créditos internacionales susceptibles de condicionalidad y ostenta una estabilidad macroeconómica basada en el manejo anticíclico de los instrumentos de política y en una regulación de flujos monetarios externos totalmente divergente con las recomendaciones del FMI (Gráfica 3; García, 2002; Marfán, 2002). El experimento de laboratorio que impulsó la dictadura de Pinochet basado en el enfoque monetarista de balanza de pagos, pudo sostenerse hasta la crisis de deuda de los ochenta, aquí y ante el intento fallido de liberación financiera que aún se lleva 1\% del presupuesto (Held y Jiménez, 1999; Held, 2002), Chile retomó una política autónoma con resultados a la vista. Creció 14 años a $7 \%$ y luego mantuvo un crecimiento promedio de 3.5\%, aunque en un contexto internacional recesivo (Stiglitz, 2001:276).

Argentina, sin la anuencia de estas instituciones ${ }^{9}$ y sin ser sujeto internacional de crédito por dos años, creció el pasado año a 7.5\% y renegoció recientemente sus compromisos crediticios en condiciones más amigables para sus intereses. Algunas lecciones importantes se rescatan de esta experiencia:

a) la experiencia argentina es contraria a una idea dominante del saber convencional [...] con que numerosos analistas perciben la disminución de los flujos de financiamiento externo y su efecto (negativo) sobre el crecimiento;

b) $[\ldots]$ cualquier arreglo institucional o ingeniería normativa por más sofisticada que sea es insuficiente para preservar los contratos o el derecho de propiedad si no se combina con un programa macroeconómico sustentable [...] lo inverso es igualmente válido. No hay sustentabilidad macroeconómica sin un sistema institucional y normativo sólido y creíble;

c) [vincula] los malos entendidos [u] errores de apreciación más recientes y difundidos [que] importan en términos del funcionamiento del sistema financiero internacional;

d) [como] reflexión/lección final que surge de la reciente negociación con el FMI [apunta dos cuestiones: [la] propiedad [o] autoría [...] de las políticas económicas [y] el timing en la aplicación de esas políticas (Lavagna, 2003:I-VI)

Brasil es un ejemplo positivo y negativo a la vez. Barros de Castro (2003:74-75) apunta la apertura tardía de la economía brasileña (1988-1994) y el desarrollo industrial que tuvo dos grandes empujes, uno anterior a los ochenta y otro posterior a 1994. Desglosa asimismo las bondades y problemas de la apertura externa (basado en la estabilidad macroeconómica y la sobrevaluación cambiaria que alentó las importaciones). A pesar de que permitió radicar en el país 430 de las 500 mayores transnacionales, y de que muchas de ellas desarrollaron tecnología comparable y superior a las fronteras sectoriales, no se generó un proceso de aprendizaje debido a que la gestión y producción de conocimientos se

9 El caso argentino es el primer desafío exitoso que pone en tela de juicio el mito de la inviolabilidad del nuevo orden internacional. Contra las amenazas de una alta funcionaria del FMI (la Dra. Anne Krueger, rescatado por Akel, 2002) que llegó a insinuar la posibilidad de embargos internacionales para disciplinar la actitud de la nueva administración (cuestión que nunca tuvo lugar, a pesar de haberse presentado siempre como espada de Damocles ante cualquier irreverencia de los gobiernos) Argentina creció, sin créditos ni flujos de capital internacional. 
encuentra en matrices foráneas. A pesar de todo pronóstico, el gobierno de Lula fue más ortodoxo en su manejo macroeconómico; no obstante, el país tiene condiciones de tamaño y liderazgo (su participación en últimos foros internacionales así lo avalan) para retomar y apoyar una agenda alternativa a la globalización dominante. La política económica brasileña no ha sido tan autónoma como se hubiera esperado de un gobierno de izquierda apoyado en una legitimidad social pocas veces vista; pese a ello, se eligió el camino de la contracción: se paró en seco su economía, como lo apuntara su ministro de Hacienda. El superávit fiscal primario acumulado para $2003(5.05 \%)$ superó con creces la meta deseable acordada con organismos internacionales (4.25\% del producto) (всв, 2003; Assis, 2004). Esto quizá se contrapuso con lo anhelado por los apoyos más íntimos del gobierno; por un lado, los empresarios que fincan sus intereses en sectores de la economía de mayor valor agregado esperaban una caída de los costos del dinero y, en el otro extremo, los sectores populares ansiaban la expansión económica (y planes de hambre-cero prometidos). ${ }^{10}$

Venezuela, con miras nacionalistas y latinoamericanistas pero con fisuras internas importantes que la mantienen en impasse, también se plantó de forma soberana ante las políticas unificadoras de estas instituciones financieras. En particular tres de las principales leyes del gobierno, energía, tierras y educación, enfrentan directamente las políticas popularizadas por las IFIs. También la política exterior de Chávez es un eje fundamental de la construcción de la soberanía nacional: así lo confirman su búsqueda de consensos en la Organización de Países Exportadores de Petróleo (OPEP) para sostener la estabilidad del precio del energético y su posición ante la deuda externa y la persecución de posiciones de conjunto (Ellner, 2002:90).

Bolivia, con el empuje de un fuerte movimiento social (mayoritariamente indígena) reemplazó al gobierno reformista en el sentido fondomonetarista de su ex presidente Gonzalo Sánchez de Lozada. Hoy, los movimientos sociales y la oposición reclaman el abandono del modelo económico vigente, incluso la nacionalización del gas y el petróleo, cuestión no contrapuesta con lo que plantea el Informe de Naciones Unidas sobre Desarrollo Humano 2004. Allí se establece la necesidad del equilibrio presupuestal con mayor recaudación e inversión pública para la búsqueda del crecimiento con equidad. Es más, el mismo Informe estipula que, en términos actuales, "la globalización en Bolivia no es sostenible" e identifica los estallidos de febrero y octubre de 2003 con el fracaso del modelo económico. Entre 1990-1998 Bolivia sólo creció 2\% anual y 1.5\% entre 1999-2001; aumentó la pobreza de 63 a 64\% de 1999 a 2002, y también el desempleo abierto, de 4.33 a 5.54\%, en el mismo periodo. Es curioso que el informe de Naciones Unidas se pregunta:

10 Incluso una de las voces más ortodoxas - económicamente hablando - la Fundación Getulio Vargas se opone al superávit primario programado para 2004, el cual sería nuevamente de $4.25 \%$ del producto. Su director, el economista Antônio Pôrto Gonçalves manifiesta que una reducción del superávit liberaría recursos de inversión, asunto por demás necesario en un contexto de alto desempleo (13\%) y una capacidad ociosa importante (Assis, 2004). 
¿Será que está en crisis la globalización en América Latina? o ¿cuán sostenible son las reformas liberales y la apertura económica implementadas en el continente? [Y, se contesta:] Sin duda, la crisis boliviana es una nueva y significativa señal del agotamiento de las políticas e ideas que orientaron el desarrollo económico latinoamericano desde finales de los 80 (PNUD, 2004:41-42). [Bolivia tiene] riesgos de integración pasiva y perversa [en las cuales] las fuerzas del mercado resuelven por sí solas la vida de todos, [en dicho sentido, la integración sería] limitada, circunscripta a unas pocas personas y empresas, mientras que la mayoría estarán más excluidos que antes. En este ámbito la democracia misma ya no es posible (PNUD, 2004:39).

México, desde la perspectiva de estas mismas instituciones internacionales, es el caso paradigmático de éxito (CEPAL, 2002b). En el periodo de más de veinte años de reformas logró convertirse en el mayor exportador de América Latina (duplicó al resto de las economías juntas), ser un gran receptor de inversión extranjera directa, y una inserción más vertical con Estados Unidos; sin embargo, esto no redundó en logros sociales importantes, sino que acrecentó la desigualdad y la pobreza (Dussel, 1996, 2001; Cypher, 2001; Delgado y Mañán, 2000, 2003). ${ }^{11}$ Un elemento que relativiza la importancia de la integración es el cambio del patrón migratorio histórico en el contexto de integración económica (Delgado, 2002; Moctezuma, 2001; García Zamora, 2003) y, en particular, la importancia de remesas para el financiamiento (infraestructura de comunidades rurales y subsistencia), al desplazar a la IED y a los créditos internaciones para tales casos (World Bank, 2004).

Uruguay, última de las crisis bancario-financieras, presenta a su vez ribetes propios, en especial lo apuntado por el FMI: reconocer el fracaso del modelo anterior (y alentar el default) y la oferta de reprogramación (refinanciación) de deuda con acreedores privados (a la postre exitosa) también tuvo su originalidad (IMF, 2004; BCU, 2004). El mismo Banco Mundial (2003) y Perry (2004) insisten ahora en reformas impositivas para países como Uruguay (Venezuela y Argentina), en donde aumentó la desigualdad, e incluso propone exenciones de IVA (impuesto al valor agregado) para productos básicos (canasta alimenticia) y el refuerzo de la tributación de artículos suntuarios (automóviles, pasajes aéreos, entre otros), así como impuestos a la renta (personal y a la propiedad) que son menores que en los países desarrollados. Este es otro de los campos en que resaltan mutaciones con las cuales se piensan hoy políticas de recaudación fiscal, por supuesto, contrapuestas a las seguidas hasta finales de los noventa y principios de siglo.

11 En trabajos anteriores apuntamos los pormenores de la dialéctica que muestra la dinámica exportadora de México y, en especial, su efecto perverso en la acumulación interna y en la mayoría de su población. En 2003, se cuestionó la evaluación que la CEPAL (2002b) hace de la competitividad, para situarlo como uno de los mejores posicionados en el comercio internacional. La CEPAL toma en cuenta el nivel técnico de bienes de exportación sin hacer referencia a la propiedad de sectores ex portadores. La irrupción reciente de China como opción distinguida (ya no plataforma de exporta ción sino potencial mercado per se) para los capitales (en particular estadounidenses) tuvo efectos lapidarios para el empleo maquilador en México y, seguramente, lo tendrá en el semimaquilador (en el cual, situamos a la industria de autopartes y automóviles). 
Al pasar a otros ejemplos de países emergentes del sudeste asiático que siguieron a México (1994) y al primer aviso brasileño (1997) en las crisis de nueva generación, tenemos que hay elementos positivos por resaltar acerca de los resultados económicos y la independencia de los países a la hora de elegir sus estrategias de política económica.

De hecho, muchos de los países a los que les fue mejor durante y después de la crisis asiática fueron aquellos que no siguieron las prescripciones estándar del FMI/Tesoro [de Estados Unidos]. China evitó una caída siguiendo políticas monetarias y fiscales expansionistas [...] Malasia siguió su propio camino y el legado de su deuda fue mucho menor [...] Con controles de capitales fue capaz de evitar la subida de los tipos de interés [...] Por el contrario, en Corea, 50\% de las empresas se vieron abocadas a la penuria, y en Indonesia, aproximadamente el 75 por ciento. Tailandia, el país que había seguido más estrechamente los consejos del FMI/Tesoro, está empezando ahora a volver a los niveles de PIB que tenía una década antes de la crisis (Stiglitz, 2001:264-265).

Corea tuvo pronta recuperación pero no gracias al programa del FMI, "sino a pesar de él". Ante la experiencia de Indonesia (donde el FMI cerró 16 bancos con un seguro muy restringido para los ahorradores), Corea nacionalizó la banca de manera eficaz y, en vez de "liberarse de la capacidad excesiva" (como exigían las políticas restrictivas del FMI) siguieron produciendo y tuvieron su recompensa cuando el mercado de chips se recuperó (Stiglitz, 2001:265).

Valga, del mismo modo, un ejemplo positivo de la incursión de políticas llevadas adelante por las IFIS. El mismo Stiglitz (2003:64-65) presenta el caso Botsuana como paradigmático; sin embargo, a pesar de que tomó estrategias de ajuste ante una crisis de liquidez, la larga experiencia del país en el manejo del consenso social explicó su éxito de gestión, antes incluso de que las recomendaciones internacionales operaran.

En dichos ejemplos resaltan: a) la suerte de las políticas apuntaladas por las IFIS, $b$ ) cierta flexibilización propia de las IFIS para reconocer sus fracasos concretos, $c$ ) fisuras entre sus socios mayoritarios, y $d$ ) nueva actitud de los países para posicionarse desde una perspectiva autónoma. Esto deja ver que los proyectos, por más sólidos que parezcan, aún cuando el grupo de los principales países industrializados los sostengan, no los exime de las contradicciones propias del proceso social que le otorga (o no) viabilidad.

\section{Consideraciones finales}

Cabe acotar que no todos los planteamientos provenientes de las IFIS son perniciosos para los intereses de los países emergentes, como sugieren las críticas más acérrimas a dichas instituciones. Incluso, algunos podrían ser funcionales para una reestructuración de formas anquilosadas de la política (amiguismo, electoralismo y politiquería en general), las cuales resultan muy ineficientes para la regulación económica. En particular, la profesionalización de cuadros administrativos (esos de contralor, i.e.: Bancos Centrales) y la evaluación 
por resultados de la gestión pública (ausente en América Latina a excepción de Chile) son, entre otros, elementos rescatables de las recomendaciones de estos organismos.

Con base en las dimensiones de las críticas institucionalizadas apuntadas, es claro que la condicionalidad estructural se encuentra severamente enjuiciada y probablemente tendrá mutaciones importantes en el futuro próximo. Los países emergentes deberían contribuir a reformular estrategias de las Instituciones internacionales de crédito, apoyados en las armas de la crítica y basados en la evaluación de la suerte de aquéllas. Resulta obvio que habrá que reclamar mayor flexibilidad por parte de los distintos staff de las IFIs para que: a) acepten programas alternativos, $b$ ) admitan visiones teóricas diversas para afrontar problemas macroeconómicos semejantes, $c$ ) reconozcan visiones de desarrollo diferentes a las sostenidas de forma oficial por estos organismos.

Un ejemplo que abona un optimismo mesurado es la Carta de Lima, emanada de la XLV Reunión Anual de las Asambleas de Gobernadores del BID, el 29 de marzo de 2004, en la capital peruana. En esta ocasión se articuló un consenso para reclamar una variación de la contabilidad exigida por las IFIS: "Inversiones y gastos corrientes constituyen hechos económicos con un impacto fiscal distinto, pero en la actualidad son tratados como si tuvieran un impacto fiscal idéntico. Ese tratamiento excesivamente simplificado, cuando es adoptado como centro de las metas fiscales, inhibe la toma de decisiones económicas racionales" (BID, 2004:1 párrafo 5). A su vez, se pretende un tratamiento diferenciado para inversiones públicas respecto del "cálculo de los parámetros a los que están sometidos los gastos corrientes” (BID, 2004:2 párrafo 8). Podría entenderse aquí una crítica en el sentido propuesto, es decir, de una de las principales debilidades de las IFIs: la evaluación cortoplacista de las externalidades de la inversión pública para el desarrollo de los países emergentes. Dicha afirmación, y resaltando de dónde viene, resulta una evaluación negativa por parte de una de las instituciones que más compartió responsabilidades y convergió teórica e ideológicamente con dichas medidas.

Los grupos antiglobalización, los países del este asiático o latinoamericanos, los de organismos con cierta independencia como la CEPAL o los intelectuales, otrora parte de estas instituciones, rechazan contundentemente:

- el trato discriminatorio que países desarrollados tienen con las naciones pobres,

- las consecuencias sociales que trajeron las reformas económicas mediante la condicionalidad estructural,

- el impacto en la soberanía nacional y en la gobernabilidad de los países, y

- la desazón que se arraiga en las sociedades ante democracias frágiles y dependientes.

Las críticas a la manera en que se piensa e implanta la "cooperación para el desarrollo" (Petras y Veltmeyer, 2003:155-164) y, en particular, a organizaciones no gubernamentales 
(ONG) como operadoras distinguidas de esa cooperación (Petras y Veltmeyer, 2003:165180), si bien pudieran develar objetivos implícitos de las IFIS, también esconden contradicciones al interior de tales instituciones y, con ello, contribuyen al inmovilismo político.

Destacamos también las contradicciones presentadas por el programa de cambio estructural de las IFIS y, a pesar de la rigidez o propiedad que aparenta en el discurso, se encubren inconvenientes no resueltos tanto para la teoría, como para la práctica de las acciones económicas y políticas llevadas a cabo.

Contra el argumento de impotencia que sostiene la poca autonomía de las políticas económicas de países latinoamericanos, el ambiente emergente, a partir de la evaluación negativa de reformas económicas de los noventa, es alentador. Tanto desde la perspectiva de quienes sostuvieron propuestas de consenso aplicable indiscriminadamente, como de críticos militantes o académicos de la globalización, bancos regionales de desarrollo o países que se enfrentaron a la fuerza de estas instituciones financieras (en especial las de Bretton Woods), se interpela el pasado reciente.

Asimismo, gana adeptos la idea de no intervención en espacios más íntimos del quehacer económico y de limitar criterios de condicionalidad al monitoreo de resultados, pero no de procesos ni tampoco de instrumentos concretos y consensuados de política económica. Se vuelven más importantes las agendas nacionales o regionales de investigación, estudios comparativos e hipótesis de trabajo, que las certezas de la tecnoburocracia de turno.

En cuanto a propuestas, se puede aceptar la idea de la CEPAL (2002, cap. vi) de instrumentar bienes públicos globales, y que uno de ellos debería ser la estabilidad macroeconómica. No obstante, también hay que aceptar los muchos caminos que conducen a Roma, es decir, diversas y divergentes formas de lograr equilibrios macroeconómicos.

Lo anterior, que podría resultar de Perogrullo para muchos académicos o investigadores de ciencias sociales, no lo es tanto para gestores políticos o decisions makers; incluso, para los críticos o las mismas oposiciones políticas latinoamericanas que avalan el argumento de los escasísimos márgenes de maniobra de la política económica. Tal vez no seamos originales al apuntar cambios en el pensamiento único que repicó en los oídos de los latinoamericanos en últimas décadas, pero sí buscamos contribuir a la esperanza de generar vías alternas y ampliar espacios autónomos que van, como lo presentamos, in crecendo.

\section{Bibliografía}

Akel, M., "La Biblia y el Calefón”, Buenos Aires, 2002, http://www.buena fuente.com

Assis, J., "Brasil-Superávit pode escandalizar até FGV"-especial-Data 19/1/2004, http://WWW. brpress.net/pautas.asp?id=108
Banco Central do Brasil, Resultado Fiscal, 2003, Brasilia, BCB, 2003, http://www4.bcb.gov.br/ pec/GCI/PORT/focus/F20030918-Resultado \%20Fiscal\%20-\%20Julho\%20de\%202003.pdf 
Banco Central del Uruguay, "Memorandum in Economic and Financial Policies 2004", http:// www.bcu.org.uy

Banco Mundial, Resumen Ejecutivo, Washington, Banco Mundial, 2000, http://worldbank.org

Barros de Castro, A., "El segundo match-up brasileño. Características y limitaciones" en Revista de la CEPAL, núm. 80, Santiago de Chile, CEPAL, agosto 2003, pp. 73-83, http://www.eclac. cl/publicaciones/

Comisión Económica para América Latina, (CEPAL), Panorama Social de América Latina y el Caribe, Santiago de Chile, CEPAL, 2002a, http://www. eclac.cl , Globalización y Desarrollo, Santiago de Chile, CEPAL, 2002b.

, Balance Preliminar de las economía de América Latina y el Caribe, 2003, Santiago de Chile, CEPAL, 2003, http://www.eclac.cl

Cypher, J., "Developing disarticulation within mexican economy", en Latin American Perspectives, vol. 28, núm. 3, California, Sage Publications, mayo, 2001, pp. 11-37.

De Ferranti, D., Perry, G. y F. Ferreira, Desigualdad en América Latina y el Caribe: ¿Ruptura con la Historia?, México, Banco Mundial, 2003, http://bancomunidal.org

Delgado, R., "La agenda oculta de la administración foxista en materia migratoria" en A. Guillén , et al., México en el primer año de gobierno de Vicente Fox, México M.A. Porrúa, 2002.

, y O.Mañán, "Mexico: the Dialectics of Export Growth" en Working Papers in International Development, núm. 00.10.2, Saint Mary’s University, Halifax, Nova Scotia, Canadá, 2000. , y O. Mañán, "Radiografía de un 'milagro' exportador: apuntes sobre el caso de México" Observatorio de la Economía Latinoamericana, España, Universidad de Málaga, 2003, http:// www.eumed.net/cursecon/ecolat/mx

Dussel Peters, E., "From export-oriented to importoriented industrialization: changes in Mexico's manufacturing sector, 1984-1994", en G. Otero, Neoliberalism Revisited: economic restructuring and Mexico's political future, Colorado, Westview Press, 1996.

__ "Ser maquila o no ser maquila, ¿es ésa la pregunta?" en Comercio Exterior, vol. 53 núm. 4, México, BNCE, abril de 2003, pp. 328-336.

Ellner, S., "The 'Radical' Thesis on Globalization and the case of Venezuela's Hugo Chávez", en Latin American Perspectives, vol. 29, núm. 6, California, Sage Publications, 2002, pp. 88-93.

Fischer, S., "Applied economics in action: IMF programs", en American Economic Review, vol. 87, núm 2, 1997, pp. 27.

Fondo Monetario Internacional (FMI), "Condicionalidad del FMI", Ficha Técnica, 4 de diciembre, 2002, http://WWW.IMF.org
García, P., "Estabilización macroeconómica con meta inflacionaria: la experiencia chilena", Banco Central de Chile, ponencia presentada en el XI Curso de Reformas Económicas y Gestión Pública Estratégica, Chile, CEPAL/ILPES, 2002.

García Zamora, R., Migración, Remesas y Desarrollo Local, México, UAZ, 2003.

George, S. y M. Wolf, La globalización liberal, Barcelona, Anagrama, 2002.

Hormats, R., "The IMF: not perfect, but essential", Brookings Review, vol.16, verano 1998, http:// www.questia.com

International Monetary Found (IMF), "Fourth Review of Uruguay's Stand-By Arrangement and Grants Waivers", Washington, IMF, 2004, http:///www.bcu.org.uy

, "Conditionality in Fund Supported Programs: External Consultations”, Washington, IMF, 2001. http:///WWW.IMF.org

_ "The ESAF at Ten Years: economic adjustment and reform in low-income countries", en Occasional papers, núm. 156, 12 de febrero de 1998, Washington D.C., IMF, 1998a.

, Distilling the Lessons from ESAF Reviews, julio de 1998, Washington D.C., IMF, 1998b.

, y World Bank, "Strengthening IMF-World Bank Collaboration on Country Programs and Conditionality", Washington, IMF-WB, 2001, http:///www.IMF.org

Kapur, D., "The IMF: a cure or a curse", en Foreign Policy, vol. 111, núm. 114, 2002, http://WwW. questia.com

Kuczynski, P. y J. Williamson, After the Washington Consensus, Institute for International Economics, 2003, http://www.iie.com y http://www.eclac.cl

Lane, T., Glosh, A., Hamman, J., Phillips, S., Schulze-Gattas, M. y T. Tsikata, "IMF-Supported programs in Indonesia, Korea, an Thailand: a preliminary assessment", en Occasional Paper, núm. 178, enero 1999, Washington D.C., IMF, 1999.

Lavagna, R., "Caso argentino. Lecciones macroeconómicas”, en Ministerio de Economía, Componentes macroeconómicos, sectoriales y microeconómicos para una estrategia nacional de desarrollo. Lineamientos para fortalecer las fuentes del crecimiento económico, Buenos Aires, Ministerio de Economía de la Nación Argentina/BID/CEPAL, mayo 2003, pp. I-IV.

Lula Da Silva, I., "Discurso de Lula en el Foro Social Mundial en Porto Alegre", en Agencia de Información Frei Tito para América Latina, 2003, http://WwW.adital.org.br/asp2/noticia.asp? idioma $=E S \&$ noticia $=5492$

Moctezuma, M., "Clubes zacatecanos en los Estados Unidos. Un capital social en proceso", presentación en el II Seminario sobre Migración Internacional, Remesas y Desarrollo Regional, Zacatecas, México, septiembre 21-22 del 2001. 
Mañán, O., "Experiencias devastadoras: moneda fuerte, acumulación débil y boom”, en Economía Informa, núm. 275, México, DEP-FE-UNAM, 1999.

Martner, R. y J. Ocampo, "La evolución de la condicionalidad de las Instituciones Financieras Internacionales. Iniciativas recientes y alternativas de políticas”, Mimeo, Chile, ILPES-CEPAL-ONU, 2002.

Marfán, M., "Una política económica con meta inflacionaria", presentación en el curso Reformas Económicas y Gestión Publica Estratégica, Chile, ILPES-CEPAL, nov.-dic., 2002.

Mekay, E., "Uma 'dura luta' pela frente, diz Lula em Davos" en World Social Forum, Porto Alegre, 27 de enero 2003, http://www.ipsnews.net/fsm 2003/27.01.2003/nota21.shtml

O'Cleireacain, S., "Governments and the IMF" and IBRD Conditionality" en S. O'Cleireacain, Third World Debt and International Public Policy, caps. 6 y 7, Nueva York, Praeger Publishers, 1990.

Perry, A., "Desigualdad en América Latina y el Caribe: ¿Ruptura con la Historia?”, presentación del trabajo del Banco Mundial en Santo Domingo, República Dominicana, 06 de Abril, 2004, http://www.prensa.com/hoy/
Petras, J. y H. Veltmeyer, La globalización desenmascarada. El imperialismo en el siglo XXI, México, UAz-Miguel Ángel Porrúa, 2003.

Programa de Naciones Unidas para el Desarrollo (PNUD), Índice de Desarrollo Humano Bolivia 2004, La Paz, PNUd/onu, 2004, http://www. Pnud.bo/Informes/2004/index.html

Ramos, J., Política económica neoliberal en países del Cono Sur de América Latina, 1974-1983, México, Siglo xxi, 1989.

Stiglitz, J., Los felices 90. La semilla de la destrucción, España, Taurus, 2001.

_, El malestar en la globalización, México, Taurus, 2002.

Valenzuela J., Crítica del Modelo Neoliberal: el FMI y el cambio estructural, México, FE-UNAM, 1991.

Williamson, J., "Diez áreas de política económica", en Apuntes de Economía de América Latina, Montevideo, CECEA, 2000.

World Bank, Global Development Finance 2003, Washington D.C, World Bank, 2004, http:// WWw. WorldBank.org/prospects/gdf2003/ 